International Journal of Molecular Medicine and Advance Sciences 15 (1): 1-4, 2019

ISSN: $1813-176 \mathrm{X}$

(C) Medwell Journals, 2019

\title{
Immunohistochemical Expression of CD44 in Glioma and its Relation to Clinicopathological Parameters
}

\author{
${ }^{1}$ Thura Abbas Fadhel and ${ }^{2}$ Hussam Hasson Ali \\ ${ }^{1}$ Department of Pathology and Forensic Medicine, College of Medicine, \\ Diyala University, Diyala, Iraq \\ ${ }^{2}$ Iraqi Board for Medical Specializations, Baghdad, Iraq
}

\begin{abstract}
Gliomas are primary brain tumors that originate from the supportive cells of the brain. Gliomas are the most common tumors of the brain in adults, accounting for almost $80 \%$ of primary malignant brain tumors for which the most common type is (glioblastoma multiforme). In Iraq, brain tumors are the fifth most common tumor in adults and the second most common in children. Their incidence was $4.77 \%$ among males and $3.3 \%$ among females. Glioma invasiveness involves the attachment of tumor cells to the brain extracellular matrix, rich in Hyaluronic Acid (HA). CD44, the principal receptor for HA is a type transmembrane glycoprotein that was initially identified as a leukocyte antigen. CD44 is the major Hyaluronan (HA) receptor, its binding to HA has been proven to participate in various tumor biological activities including tumor progression, metastasis and proliferation, so, it can play a critical role in cell migration and extravasation. Assessment of CD44 expression in different types of gliomas. Correlation between CD44 scoring and patient's age, sex and tumor grading. The reliability of using CD44 as diagnostic marker in gliomas. Forty cases of glioma where included in this study, they were collected from Al-Shaheed Ghazi Al Hariri Hospital in Baghdad medical city from January, 2016 through December, 2017. Their age ranging between (1-56) years with mean age of 31.4 year polymer based immunohisto chemichal technique was used for detection of CD44 antibody. Patients with grade I and IV were predominant the studied samples and composed each of $32.5 \%$ of whole samples while grade II and III represent $25,10 \%$, respectively. CD 44 was positively expressed in $97.5 \%$ of cases but without significant statistical correlation with grade, age and sex. There is positive correlation between age and grade of tumors. From the above results we conclude that CD44 play important role in pathogenesis of glioma due to its high expression in alltumor grades but without positive correlation with histological types.
\end{abstract}

Key words: CD44 expression, glioma, astrocytoma, immunohisto chemistry, technique, biological

\section{INTRODUCTION}

Gliomas are the most common tumors of the brain in adults accounting for almost $80 \%$ of primary malignant brain tumors and are responsible for approximately 15,000 cancer death in United States each year. The most common type of gliomas (glioblastoma multiforme) is associated with median survival of only $12-15$ months. In Iraq, brain tumors are the fifth most common tumor in adults and the second most common in children. They represented about $4.77 \%$ among males and $3.3 \%$ among females (Anonymous, 2016).

The World Health Organization (WHO) published a classification system of central nervous system tumors in 1979 and subsequently revised the system in 2000, 2007 and 2016. In 2016 system, the major neuroepithelial tumors include astrocytic, oligodendroglial, oligoastrocytic, ependymal and choroid plexus tumors. The grading of gliomas mainly relies on histological features including cellularity, nuclear atypia, mitotic activity, vascularity and necrosis, observed on light microscopy (Windt et al., 2011) with the aid of immunohisto chemistry (Jaiswal, 2016).

Glioma invasiveness involves the attachment of tumor cells to the brain extracellular matrix, rich in Haluronic Acid (HA). CD44 as a standard molecule (CD44s) or as variants (CD44v) is the major Haluronan (HA) receptor and $\mathrm{CD} 44$ bound to $\mathrm{HA}$ has been proven to participate in various tumor biological activities including tumor progression, metastasis and proliferation (Windt et al., 2011). CD44 plays a critical role in cell migration with involvement in multiple steps. Once activated, the cytoplasmic tail of CD44 interacts with the actin cytoskeleton and CD44 is induced to the leading edge of migrating cells (Orian-Rousseau, 2010).

\section{Aim of study:}

- Assessment of CD44 expression in different types of gliomas

Corresponding Author: Thura Abbas, Department of Pathology and Forensic Medicine, College of Medicine, Diyala University, 00964 Diyala, Iraq Tel: 07715737399 
Int. J. Mol. Med. Adv. Sci., 15 (1): 1-4, 2019

- Correlation between CD44 scoring and patient's age, sex and tumor grading

- The reliability of using CD44 as diagnostic marker in gliomas

\section{MATERIALS AND METHODS}

In this retrospective study, a total of 40 formalin-fixed paraffin-embedded brain excisional biopsies from Iraqi patients covering the period from January, 2016 to December, 2017, the cases were already diagnosed by $\mathrm{H} \& \mathrm{E}$ and retrieved from the archival materials in Al Shaheed Ghazi Al Hariri Hospital.

\section{Immunohisto chemical staining procedure:}

- About $5 \mu$ sections were obtained from formalin fixed-paraffin embedded tissue blocks and mounted on positively charged slides

- Slide baking: in a drying oven (hot air oven) at $65^{\circ} \mathrm{C}$ over night

- De-paraffinizing and rehydration: from xylene to distilled water

- Antigen retrieval apply to the slides then washed with distilled water

- PAP pen was used to draw a circle around the tissue section

- Peroxidase block: enough drops of peroxidase block reagent were applied onto the tissue then rinsed gently with buffer for a minimum of $15 \mathrm{sec}$

- Primary antibody (CD44): primary antibody was applied onto each section

- Poly excel target binder: cover the tissue section with target binder and then placed in a fresh buffer

- Poly excel poly HRP: cover the section with polly excel poly HRP and incubate for $10 \mathrm{~min}$ at room temperature in humid chamber and then placed in fresh buffer bath for $5 \mathrm{~min}$

- Substrate-chromogen solution: chromogen reagent was applied on each section then placed in a buffer bath for $5 \mathrm{~min}$

- Hematoxylin counter stain solution were applied covering the whole section and incubated at room temperature for $5 \mathrm{~min}$. After that, the slides were rinsed gently with distilled water then drained and bottled

- Aqueous-base mounting medium were applied onto the tissue sections and covered with cover slips and left to dry

Quality control: Negative control: transitional cell carcinoma of bladder. Positive control (as recommended by the leaflet). Skin as shown in photomicrograph.

Evaluation of immunostaining: Positive staining of CD44 was defined as membranous and/or cytoplasmic staining pattern of epithelial tumor cells (6), even if the staining was focal in the tumor cells, the positive stain appear brown colour, regardless of staining intensity. The immunohisto chemichal results for CD44 were scored according to four grades as follow (Ng and Lo, 1989):

- No positive cells (score 0 )

- $<25 \%$ positive cells ( score 1 )

- Between $25-75 \%$ positive cells (score 2 )

- More than $75 \%$ positive cells (score 3)

Statistical analysis: Statistical analysis was performed with SPSS V 18.88 (Statistical Package for Social Sciences) p-values were considered statistically significant when equal or $<0.05$.

\section{RESULTS AND DISCUSSION}

Clinicopathological analysis: Forty cases of glioma were included in this study. Their ages were ranging from 1-56 year with the most frequent age (25\%) were in the $3 \mathrm{rd}$ decade of life.

Regarding gender, female to male ratio was (1.12). The predominant grades were grade I and grade IV with 13 cases for each $(32.5 \%)$. Whereas patient of grade II and III compose $10(25 \%), 4(10 \%)$ cases, respectively (Table 1).

Correlation between CD44 score and age of studied patients: Figure 1 show the relation between age of studied patients and CD44 score which indicate that there is no significant correlation between them ( $p$ value 0.304).

Correlation between CD44 score and sex of patients: The results of CD44 score in relation to sex show no significant correlation ( $p$ value 0.813 ) as shown in the Table 2.

Correlation between CD44 score and grade of studied cases: Table 3 show the relation of CD44 score and tumors grade which reveals that there is no significant correlation between them ( $p$ value 0.968 ).

Gender distribution: In this study, it was found that gliomas are slightly more common in female than in males, $52.5 \%$ compared to $47.5 \%$. There was no difference between different grades of glioma regarding sex distribution.

This disagree study by Tsidulko et al. (2017) found that there is slight male predominance which is $55.4 \%$, compared to females $44.6 \%$ with male to female ratio 1.242:1. Tsidulko et al. (2017), other study by Fakhari et al. (2018) show also male predominance as $62.6 \%$ with females only $37.3 \%$. 
Int. J. Mol. Med. Adv. Sci., 15 (1): 1-4, 2019

Table 1: Baseline characteristics of cases

\begin{tabular}{|c|c|c|c|c|c|c|c|}
\hline \multirow[b]{3}{*}{ Grades } & \multirow[b]{3}{*}{ No. } & \multirow{2}{*}{\multicolumn{2}{|c|}{ Age (Years) }} & \multicolumn{4}{|c|}{ Gender } \\
\hline & & & & \multicolumn{2}{|c|}{ Male } & \multicolumn{2}{|c|}{ Female } \\
\hline & & Means $\mp$ SD & Range & No. & Percentage & No. & Percentage \\
\hline $\mathrm{I}$ & 13 & $9.923 \mp 7.065$ & $1.0-20$ & 9 & 69.231 & 4 & 30.769 \\
\hline II & 10 & $31.1 \mp 9.159$ & $5.0-39.0$ & 6 & 60 & 4 & 40 \\
\hline III & 4 & $48.75 \mp 4.65698$ & $42.0-55.0$ & 0 & 0 & 4 & 100 \\
\hline IV & 13 & $47.846 \mp 7.284$ & $30.0-56.0$ & 4 & 30.769 & 9 & 69.231 \\
\hline Total & 40 & $31.425 \mp 18.0151$ & $1-56$ & 19 & 47.5 & 21 & 52.5 \\
\hline
\end{tabular}

Table 2: Correlation between CD44 score and patient sex

\begin{tabular}{lccc}
\hline CD44 score & Females $(\mathrm{N}=21)$ & Males $(\mathrm{N}=19)$ & $\mathrm{p}$-value \\
\hline 0 & 0 & 1 & $0.813^{* *}$ \\
1 & 1 & 1 & 4 \\
2 & 8 & 13 & \\
3 & 12 &
\end{tabular}

Table 3: Correlation between CD44 score and grade

\begin{tabular}{|c|c|c|c|c|c|c|}
\hline \multirow[b]{2}{*}{ CD44 score } & \multicolumn{4}{|l|}{ Grades } & \multirow[b]{2}{*}{ Total } & \multirow[b]{2}{*}{$\mathrm{p}$-values } \\
\hline & I & II & III & IV & & \\
\hline$\overline{0}$ & $0(0.0 \%)$ & $1(10.0 \%)$ & $0(0.0 \%)$ & $0(0.0 \%)$ & 1 & $0.968^{*}$ \\
\hline 1 & $1(7.7 \%)$ & $1(10.0 \%)$ & $0(0.0 \%)$ & $0(0.0 \%)$ & 2 & - \\
\hline 2 & $3(23.1 \%)$ & $2(20.0 \%)$ & $2(50.0 \%)$ & $5(38.5 \%)$ & 12 & - \\
\hline 3 & $9(69.2 \%)$ & $6(60.0 \%)$ & $2(50.0 \%)$ & $8(61.5 \%)$ & 25 & - \\
\hline Total & 13 & 10 & 4 & 13 & 40 & - \\
\hline
\end{tabular}

*Yate's Chi square

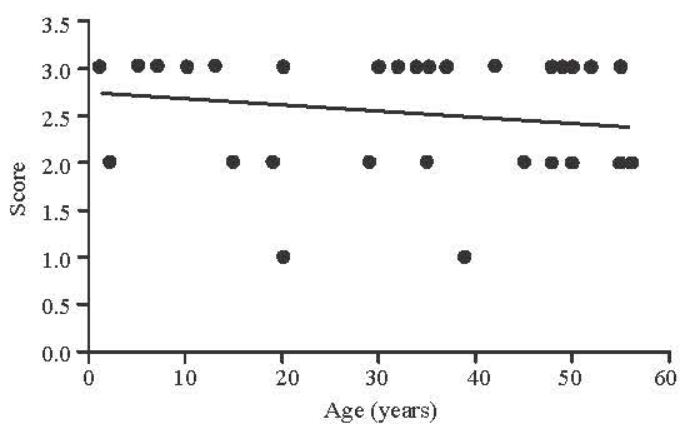

Fig. 1: Relation between age of studied patients and CD44 score

This differences in results may be due to hormonal effect as shown in our result the predominance of female gender or ethnical variation as mentioned in previously the increased incidence in white population, for example or environmental factors such radiation effect and occupational exposure or small number of patients studied in comparison with above mentioned studies.

Age distribution: The results of this study show that the mean age of patient with grade $111,1 \mathrm{~V}$ are higher than that of grade I, II glioma tumor. The age range of patient was (1-56) years. Which is disagree with the study by Tsidulko et al. (2018) which found that there was no correlation between age and grade, there age range was (48-51) year. By Fakhri et al. (2018) the age range was
(40-71) year which has also no significant correlation with tumor grade. The differences in results between Fakhari and this study may be due to wide range used by our study as they include adults and old age groups only or could be due to large number of selected cases in comparison with this study $(67,75,40)$ case, respectively (Fig. 2 and 3 ).

Tumor grade: In this study, the majority of cases were of grade I, IV with equal percentage (13) case each while grade 11 (Ylagan and Quinn, 1997) cases and grade 111 (4) cases. Similarly, Sima et al., show that the majority of their cases were high grade tumor (111, IV) as 36 cases and (31) cases for low grade tumor (1, 11). Also, by Alexandra et al., study, the largest number fir grade IV (61) case, grade 11 (7) cases and grade 111 (7) cases.

This differences in grade frequency among different studies may suggest geographical or environmental causes as Iraqi study show predominance of both grade 1 and $1 \mathrm{~V}$ while worldwide, only grade IV predominates.

In this study, CD44 positive expression was found in nearly all glioma grades with various degree of expression (various score). Score 0 was expressed in only 1 case $(2.5 \%)$ of grade 11 , score 1 in 2 cases $(5.0 \%)$, score 2 in 12 case $(30 \%)$ and score 3 in 25 case $(62.5 \%)$. This results were supported by the (Ylagan and Quinn, 1997) show $89 \%$ of grade $1,90 \%$ of grade 11 , $76 \%$ of grade $111,84 \%$ of of grade IV are immun reactive 


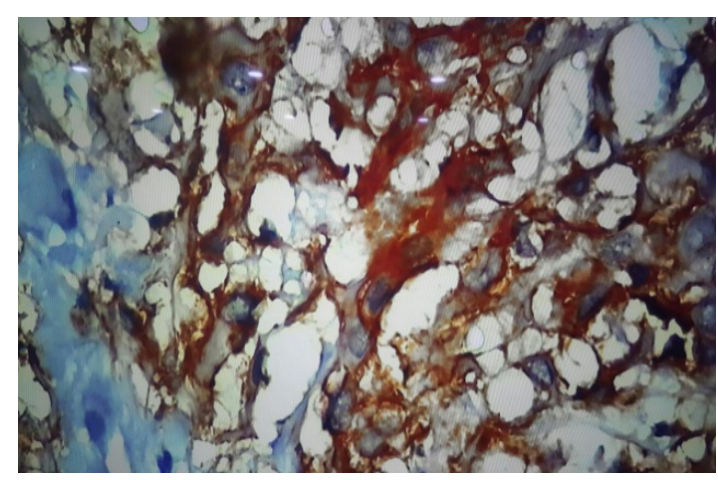

Fig. 2: Pilocytic astrocytoma with piloid and microcystic areas, show strong membranous (score 3 ) staining with CD44 antibody (40X)

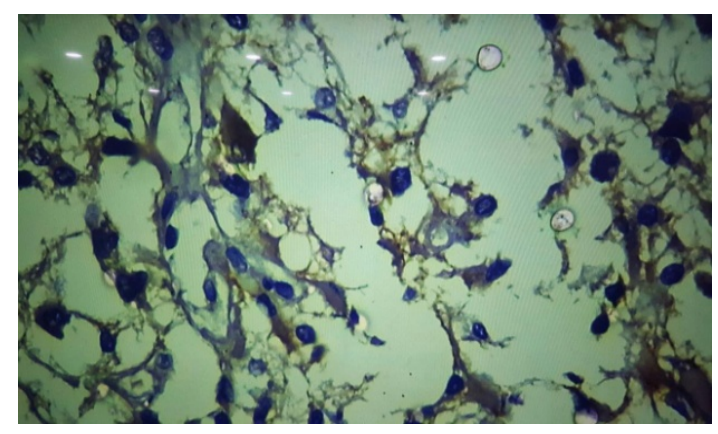

Fig. 3: Epyndymoma, WHO grade II with characteristic monomorphic cells with round to oval nuclei, showing score (1) CD44 immunoreactivity (40X)

for $\mathrm{CD} 44$ with 2 or 3 score. This results indicate that there is no correlation between glioma grade and CD44 score.

Other studies show different finding regarding CD44 expression by Fakhari et al. (2018) $(65.67 \%, 44 / 67)$ were positively stained by CD44 with $(\mathrm{p}<0.01)$.

By Yoshida et al. (2012) there is increase expression of CD44 in high grade tum or in comparison with low grade and normal brain tissue, so, it is correlate with histopathological grade of glioma. Regarding also there is positive significant correlation $(p<0.05)$ between glioma grade and CD44 expression which manifested by low level expression in grade 11, 111 and high score (Windt et al., 2011) in grade lV (Wei et al., 2010).

Such discrepancies may be due to environmental, racial and geographic differences in addition to the differences in sample size and antibody used to detect CD44 antigen heterogenicity of expression of CD44 within the tumor and the use of different staining protocols.

\section{CONCLUSION}

The majority of cases were of grade 1 and $1 \mathrm{~V}$ glioma with female predominance. CD44 was positively expressed in $97.5 \%$ of the studied cases of glioma. There is significant correlation between tumor grade and age.

There is no significant relationship between CD44 expression and tumor grade, age and sex, hence and according to the results of this study, CD44 may be not useful ancillary test to asses tumors malignant potential and invasiveness nor to distinguish between different histological grades and types of glioma.

\section{ACKNOWLEDGEMENTS}

The researchers thank the Ministry of Higher Education and Scientific research/Iraq for their financial support. Thura Abbas Fadhel contributed in collection of cases, IHC workup, writng of study. Hussam Hasson Ali contribute in study design and supervision of research.

\section{REFERENCES}

Anonymous, 2016. Iraqi Cancer registry. Ministry of Health, Baghdad, Iraq.

Fakhari, S.A., A.Z. Mehrjardi and M. Noori, 2018. Expression of CD44 and CD133 in glioma stem cells. Intl. J. Tumor Therapy, 7: 27-33.

Jaiswal, S., 2016. Role of immunohistochemistry in the diagnosis of central nervous system tumors. Neurol. India, 64: 502-512.

Ng, H.K. and T.H. Lo, 1989. Cytokeratin immunoreactivity in gliomas. Histopathol., 14: 359-368.

Orian-Rousseau, V., 2010. CD44, a therapeutic target for metastasising tumours. Eur. J. Cancer, 46: 12711277.

Tsidulko, A.Y., G.M. Kazanskaya, D.V. Kostromskaya, S.V. Aidagulova, R.S. Kiselev, A.M. Volkov and E.V. Grigorieva, 2017. Prognostic relevance of NG2/CSPG4, CD44 and Ki-67 in patients with glioblastoma. Tumor Biol., Vol. 39,

Wei, K.C., C.Y. Huang, P.Y. Chen, L.Y. Feng, T.W.E. Wu, S.M. Chen and P.C. Pai, 2010. Evaluation of the prognostic value of CD44 in glioblastoma multiforme. Anti Cancer Res., 30: 253-259.

Windt, G.J.V.D., M. Schouten, S. Zeerleder, S. Florquin and T.V.D. Poll, 2011. CD44 is protective during hyperoxia-induced lung injury. Am. J. Respir. Cell Mol. Biol., 44: 377-383.

Ylagan, L.R. and B. Quinn, 1997. CD44 expression in astrocytic tumors. Mod. Pathol. J., 10: $1239-1246$.

Yoshida, T., Y. Matsuda, Z. Naito and T. Ishiwata, 2012. CD44 in human glioma correlates with histopathological grade and cell migration. Pathol. Intl., 62: 463-470. 